\title{
Study on the Effect of the Oil-Water Ratio on the Rheological Properties of Hydroxyethyl Cellulose (HEC)
}

\author{
Xiaoming Su $(\mathbb{D}$, Zhanghua Lian $(\mathbb{D}$, and Yuan Yuan \\ State Key Laboratory of Oil and Gas Reservoir Geology and Exploitation, Southwest Petroleum University, Chengdu, China \\ Correspondence should be addressed to Xiaoming Su; sxm310426@126.com
}

Received 18 November 2018; Revised 22 February 2019; Accepted 1 April 2019; Published 22 July 2019

Guest Editor: Bisheng Wu

Copyright ( 2019 Xiaoming Su et al. This is an open access article distributed under the Creative Commons Attribution License, which permits unrestricted use, distribution, and reproduction in any medium, provided the original work is properly cited.

\begin{abstract}
Hydroxyethyl cellulose (HEC) is widely used in water-base drilling fluid as tackifier because of its good fluidity, stability, propcarrying capacity, and good reservoir protection, while it has insufficient rheological property under higher temperature. In order to make use of its advantages and improve thermal stability, an innovative method that HEC was dissolved in the emulsion was proposed. Research indicated that compared with traditional water solution, the oil-water emulsion as solution could effectively improve the rheological properties and thermal stability. The oil-water ratio has an obvious effect on rheological properties. Firstly, with the decrease in the oil-water ratio, the apparent viscosity and shear stress were decreased; secondly, under constant oil-water ratio or temperature, the larger the shear rate, the lower the apparent viscosity, and the greater the shear strength; lastly under extremely low shear rate, HEC emulsion's viscosity peaked at more than $50000 \mathrm{mPa} \cdot \mathrm{s}$, which can effectively solve the problem of sand carrying difficulty and being easy to form sand bed in horizontal well and high angle hole. In addition, the emulsifying stability was degradative with the increase in the oil-water ratio. The degradation was not obvious when the oil-water ratio was less than 30:70. On the contrary, the performance deteriorated drastically when the oil-water ratio was greater than $30: 70$. The separator liquid was more than $2 \mathrm{~cm}$ and was even about $1 / 3$ when the oil-water was $50: 50$. On the basis of analysis of the experimental results, we can see that oil-water emulsion could effectively improve the rheological stability and thermal stability of HEC and the optimal oil-water ratio was $30: 70$. This study provided a new thought for application of HEC or other polymers in drilling fluid.
\end{abstract}

\section{Introduction}

Drilling fluid known as the "engineering blood" plays an indispensable role in cooling the bit, lubricating the tool, breaking the rock and carrying the debris to the wellhead, balancing the formation pressure, protecting the borehole, transferring the water power, and forming a mud cake on the borehole wall which protect reservoirs and reduce the damage caused by drilling engineering [1-6]. Smooth and efficient drilling operation highly depends on drilling fluid systems with required rheological, fluid filtration, and hightemperature properties in a low-cost and ecologically friendly manner. Generally, two types of drilling fluids including water-based drilling fluids, oil-based drilling fluids, and synthetic-based drilling fluids are used in various drilling conditions. Due to lower environmental impact and lower cost, water-based drilling fluids are extensively used [7].
However, in circumstances such as reactive shales, directional drilling, and high-temperature and high-pressure (HTHP) formations, operators may have to consider oilbased drilling fluids. Compared with water-based drilling fluids, oil-based drilling fluids show better wellbore geomechanical stability, thermal stability, lower friction and drag, and increased drilling efficiency [8-12].

One of the most severe of drilling fluid is the rheological property, which affects removal of cuttings, holding cuttings, and weight material in suspension when not circulating and under a higher temperature [5, 6]. However, oil-based drilling fluid improves the carrying capacity through adding organic clay. There is no doubt that the tackifying effect is poorer than that of the traditional tackifier. Most of all, the addition of organic clay raises solid content in drilling fluid, which is negative for reservoir protection and easily causes reservoir damage [13-15]. So we need to find a new way to 
decrease the solid content in drilling fluid on the basis of satisfying holding cuttings and suspension demand.

HEC is a tasteless and nontoxic fiber where hydrogen of the hydroxyl group of cellulose is replaced by ethylol as shown in Figure 1 [16]. It has good performances, such as good tackifying performance, suspension, bonding, adhesion, moisture-retaining property, insensitivity to salt, and reservoir protection, and is widely used in water-based drilling fluid as a water-soluble polymer, but its temperature resistance is poorer [17-20]. However, it is rarely used in oil-based drilling fluid. In order to take full advantage of both good tackifying performance, suspension, bonding, adhesion, moisture-retaining property, and reservoir protection of HEC as well as low friction, high rate of penetration, shale inhibition, wellbore stability, high lubricity, salt resistance, and thermal stability of oil-based drilling fluid, we try to dissolve HEC into oil-water emulsion to decrease the solid content of drilling and improve the temperature resistance of HEC to meet deep-well drilling, which puts forward new ideas for the application of HEC in drilling completion fluid and could make use of polymerides.

\section{Experiment}

2.1. Experimental Apparatus. Experimental installations used were an M3600 automatic rheometer (from Grace Instrument Inc.), a senior speed stepless speed mixer (from Qingdao Tongchun), and a heating device (from Qingdao Tongchun).

2.2. Experimental Reagent and Condition. Experimental reagents include $\mathrm{HEC}, \mathrm{NaOH}, \mathrm{Na}_{2} \mathrm{CO}_{3}, \mathrm{ZR}-01$, and $0^{\#}$ oil. HEC is a kind of tackifier; it has a density of $0.75 \mathrm{~g} / \mathrm{cm}^{3}$ and the molar degree of substitution is 18 2.0.

Basic formula is $0^{\#}$ oil $+0.2 \% \mathrm{NaOH}+0.25 \% \mathrm{Na}_{2} \mathrm{CO}_{3}+$ $3.0 \%$ emulsifier ZR $-01+0.6 \%$ HEC. The experimental condition is shown in Table 1.

2.3. Experimental Procedure. The value of the oil-water ratio was usually $90: 10-20: 80$, considering the environmental pollution and the cost of drilling fluid; the value of oilwater is $50: 50,40: 60,30: 70,20: 80,10: 90$, and $0: 100$ (oil-free, respectively). The experimental procedures were as follows.

(I) A certain amount of HEC was slowly added to the diesel emulsion with a different oil-water ratio and stirred at $10000 \mathrm{r} / \mathrm{min}$ high speed for $60 \mathrm{~min}$ to prepare HEC emulsion

(II) The rheological parameters of the HEC emulsion solution were measured at a constant shear rate $\left(1021.8 \mathrm{~S}^{-1}, 510.9 \mathrm{~S}^{-1}, 340.6 \mathrm{~S}^{-1}, 170.3 \mathrm{~S}^{-1}, 10.2 \mathrm{~S}^{-1}\right.$, and $5.1 \mathrm{~S}^{-1}$ ) to evaluate the effect of the oil-water ratio on rheological property at certain temperatures $\left(30^{\circ} \mathrm{C}, 60^{\circ} \mathrm{C}, 80^{\circ} \mathrm{C}, 90^{\circ} \mathrm{C}\right.$, and $\left.100^{\circ} \mathrm{C}\right)$.

(III) The rheological parameters of the HEC emulsion solution have oil-water ratios of, respectively, $50: 50,40: 60,30: 70,20: 80,10: 90$, and $0: 100$

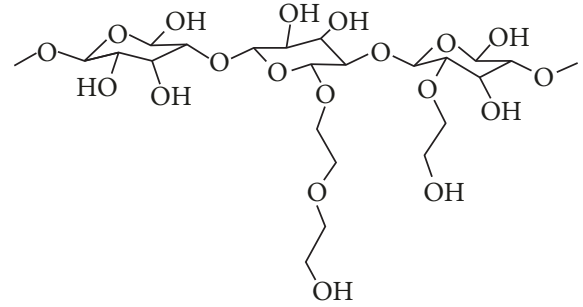

Figure 1: Diagram of the HEC molecular structure.

(oil-free) which were measured under constant temperature $\left(30^{\circ} \mathrm{C}, 90^{\circ} \mathrm{C}\right)$.

(IV) At a certain temperature $\left(30^{\circ} \mathrm{C}, 90^{\circ} \mathrm{C}\right)$, the rheological parameters of HEC emulsion were measured to evaluate the effect of the oil-water ratio on static suspension capacity at a lower shear rate

(V) Let the HEC emulsion stand for 48 hours at room temperature in a colorimetric tube, and then observe the change and difference between the upper and lower sections in the colorimetric tube to evaluate the emulsion stability

(VI) A hot rolling experiment was adopted to evaluate the effect of the oil-water ratio on emulsion stability at different temperatures

\section{Results and Analysis}

Polymer hydroxyethyl cellulose is widely used in the petroleum industry, especially in drilling, completion, workover, and fracturing processes. As drilling completion fluid additives, HEC can effectively reduce the hydrodynamic friction, decrease the starting torque, and protect the production layer. Moreover, the application of HEC is more prominent in hard rock. In this study, the rheological properties of the HEC solution were measured used a viscometer, M3600, at a constant shear rate, constant temperature, constant oilwater ratio, and low shear rate to evaluate the effect of the oil-water ratio on the rheological ability of HEC emulsion. Besides, emulsion stability of HEC emulsion with a different oil-water ratio were measured using two methods, hot rolling and standing and the layering process, to evaluate the effect of the oil-water ratio on emulsion stability of HEC emulsion.

3.1. Constant Shear Rate. The rheological parameters of different oil-water ratio emulsions $(50: 50,40: 60,30: 70$, $20: 80,10: 90$, and $0: 100$ (oil-free)) were measured at a constant shear rate $\left(1021.8 \mathrm{~S}^{-1}, 510.9 \mathrm{~S}^{-1}, 340.6 \mathrm{~S}^{-1}, 170.3 \mathrm{~S}^{-1}\right.$, $10.2 \mathrm{~S}^{-1}$, and $\left.5.1 \mathrm{~S}^{-1}\right)$. The results are shown in Figures 2 and 3.

The results shown in Figure 2 revealed that the viscosity of HEC emulsion was continuously reduced with the decrease in the oil-water ratio at six kinds of different constant shear rates. When the oil-water ratio was more than $30: 70$, the viscosity dropped obviously with the decrease in the oil-water ratio, and when it was less than $30: 70$, the 
TABLE 1: The experimental conditions.

\begin{tabular}{|c|c|c|}
\hline Items & Function & Remarks \\
\hline Oil-water emulsion & Base & The oil-water rate is $50: 50,40: 60,30: 70,20: 80,10: 90,0: 100$ (oil free), $0^{\#}$ oil \\
\hline ZR-01 & Emulsifier & $3.0 \%$ \\
\hline HEC (hydroxyethyl cellulose) & Viscosifier & $0.6 \%$ \\
\hline $\mathrm{NaOH}$ & $\mathrm{pH}$ control & $0.2 \%$ \\
\hline $\mathrm{Na}_{2} \mathrm{CO}_{3}$ & Additive & $0.25 \%$ \\
\hline Heating device & Thermal evaluation & The temperature is $30,60,80,90,100^{\circ} \mathrm{C}$ \\
\hline M3600 (automatic rheometer) & Rheological evaluation & $1021.8 \mathrm{~S}^{-1}, 510.9 \mathrm{~S}^{-1}, 340.6 \mathrm{~S}^{-1}, 170.3 \mathrm{~S}^{-1}, 10.2 \mathrm{~S}^{-1}$, and $5.1 \mathrm{~S}^{-1}$ and $60^{\circ} \mathrm{C}$ and $90^{\circ} \mathrm{C}$ \\
\hline Senior speed stepless mixer & Stirrer & Mixing time is $60 \mathrm{~min}$, and the speed must be more than $10000 \mathrm{r} / \mathrm{min}$ \\
\hline Colorimetric tube & $\begin{array}{l}\text { Emulsion stability } \\
\text { analysis }\end{array}$ & $\begin{array}{c}\text { The oil-water rate is } 50: 50,40: 60,30: 70,20: 80 \text {, and } 10: 90 \text {, at room } \\
\text { temperature }\end{array}$ \\
\hline
\end{tabular}

reduction was lesser. When the oil-water ratio was reduced from $50: 50$ to $30: 70$, the viscosity of HEC emulsion solution decreased dramatically, reducing the rate of up to $87.6 \%$, at $30^{\circ} \mathrm{C}$ and $5.1 \mathrm{~s}^{-1}$. Comparing the HEC emulsion solution of the oil-water ratio of $50: 50$ with that of $0: 100$, it was found that when the water was reduced by double, the viscosity was increased 72 times at the temperature of $30^{\circ} \mathrm{C}$, which expressed that oil-water emulsion is better than aqueous as solution for HEC. At a high shear rate of $1021.8 \mathrm{~S}^{-1}$ and experimental temperature of $30^{\circ} \mathrm{C}$, we can see that the viscosity difference between 50:50 and 30:70 was more obvious, and the value was $100 \mathrm{mPa} \cdot \mathrm{s}$. At the same changes in the oil-water ratio, the viscosity was reduced with the increase in temperature in the same shear rate. Although the viscosity of HEC emulsion $(50: 50)$ decreased to $61.5 \mathrm{mPa} \cdot \mathrm{s}$ at a shear rate of $1021.8 \mathrm{~S}^{-1}$, the solution still had a certain viscoelasticity when the temperature was increased from $30^{\circ} \mathrm{C}$ to $100^{\circ} \mathrm{C}$. In contrast, under the same condition, the viscosity of the HEC emulsion solution $(30: 70)$ decreased to $11 \mathrm{mPa} \cdot \mathrm{s}$, leading to loss in viscoelasticity, and the solution with the oil-water rate of less than 10:90 almost lost its viscoelasticity. According to Figure 2, we can see that compared with the viscosity of HEC brine solution, oil-water emulsion could obviously enhance the tackifier performance and improve the rheological property of HEC.

The experimental results of shear stress are listed in Figure 3. It can be seen that shear stress was decreased continuously with the reduction in the oil-water ratio of HEC emulsion. When the value is over 20:80, shear stress decreased nonlinearly; when it was less than $20: 80$, the trend was approximately linear, but the degree of diminution was less several times than the former. Meanwhile, compared with the change in viscosity along with the oil-water ratio, the shear stress has a steady decline with the increase in temperature, which was similar to the trend of viscosity decline. Under the constant shear rate $1021.8 \mathrm{~S}^{-1}$, the HEC emulsion $(50: 50)$ displayed stronger shear stress, whose characteristics were bad for drilling. Under the same condition, the HEC emulsion (20:80) displayed low shear stress and the value is only half of $50: 50$ at $30^{\circ} \mathrm{C}$.

We can see from Figures 2 and 3 that with the decrease in the oil-water ratio, HEC's viscosity and shear stress both were decreased. With the increase in temperature, HEC's viscosity and shear stress also were decreased continuously, which keeps good consistency in the process of the rise in temperature. This phenomenon conformed to Arrhenius' equation,

$$
\ln \eta=\ln A+\frac{\Delta E}{R T}
$$

where $\Delta E$ is the activation energy, $\eta$ is the viscosity, $R$ is the universal gas constant, and $T$ is temperature. Arrhenius' equation indicated that the fluid viscosity was decreased with the increase in temperature, which has good consistency with experimental results (Figure 2).

The results from experiments and Arrhenius' equation were in good agreement with each other, and it was consistent with the law of fluid flow. The experimental results showed that the HEC solution used diesel oil emulsion as solvent which is a good pseudoplastic fluid, which can be used to prepare an ideal drilling and completion fluid system.

3.2. Constant Temperature $\left(30^{\circ} \mathrm{C}, 90^{\circ} \mathrm{C}\right)$. In the test of $\mathrm{HEC}$ emulsion rheological stability, we set up $30^{\circ} \mathrm{C}$ and $90^{\circ} \mathrm{C}$ as the experimental temperature. The rheological experimental results with different oil-water ratios of $50: 50,40: 60$, $30: 70,20: 80,10: 90$, and $0: 100$ (oil-free) HEC oil-water emulsion are shown in Figures 4 and 5.

It can be drawn from Figures 4 and 5 that the apparent viscosity and shear stress had an obvious decrease with the decrease in the oil-water ratio at constant temperatures $30^{\circ} \mathrm{C}$ and $90^{\circ} \mathrm{C}$. We can see that the viscosity increased linearly with the decrease in shear rate and the increase in amplitude was smaller when the shear rate was greater than $170.3 \mathrm{~S}^{-1}$, and it has increased sharply when the shear was lower than $170.3 \mathrm{~S}^{-1}$, whose changes kept a good consistency with the temperature $90^{\circ} \mathrm{C}$. And, whether it is at higher temperature $\left(90^{\circ} \mathrm{C}\right)$ or lower temperature $\left(30^{\circ} \mathrm{C}\right)$, the $\mathrm{HEC}$ emulsion solution had a better rheological property and the apparent viscosity was always greater than the HEC brine solution. Besides, we can see that emulsion can improve the high-temperature resistance of the HEC 


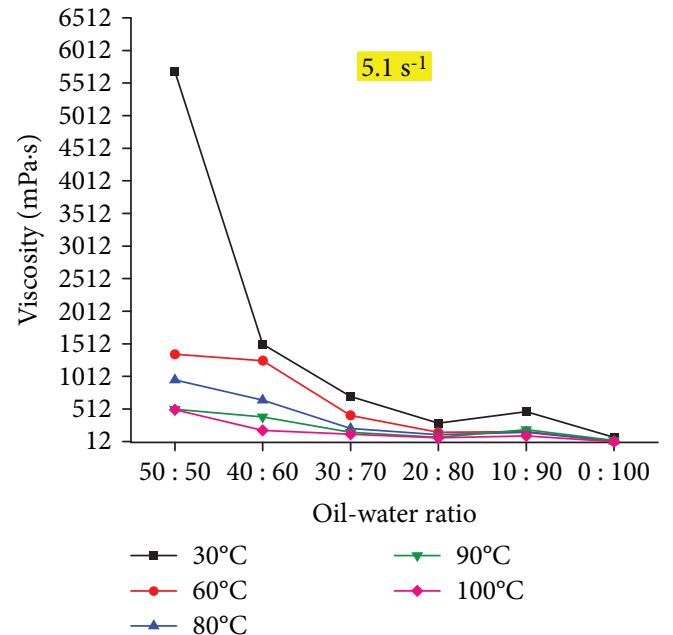

(a)

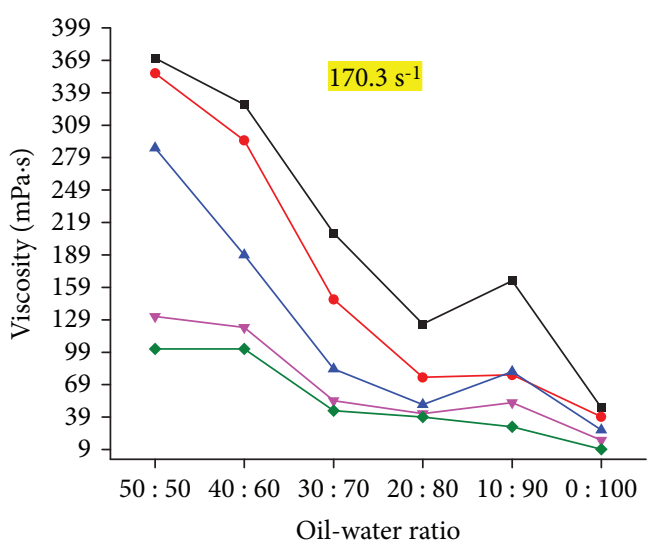

$-30^{\circ} \mathrm{C}$

$\rightarrow 60^{\circ} \mathrm{C}$

$\simeq 80^{\circ} \mathrm{C}$

(c)

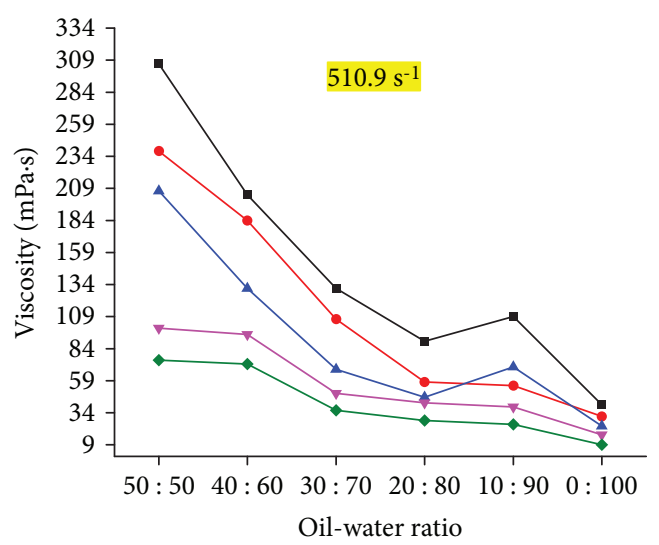

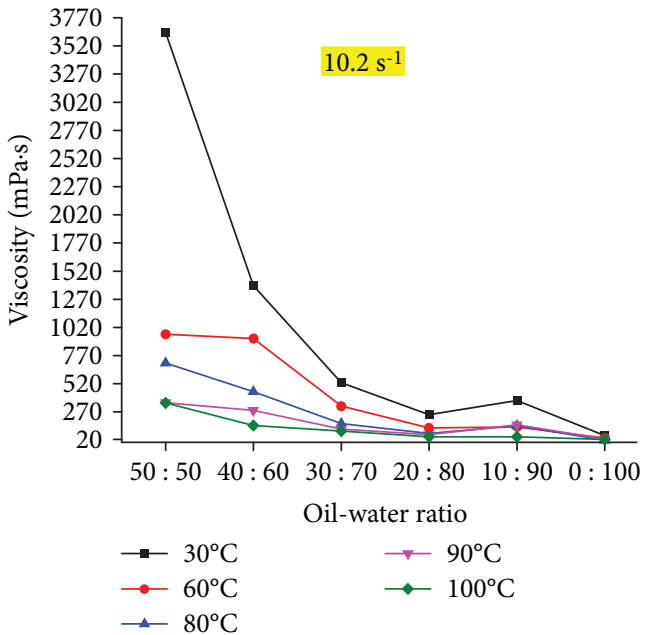

(b)

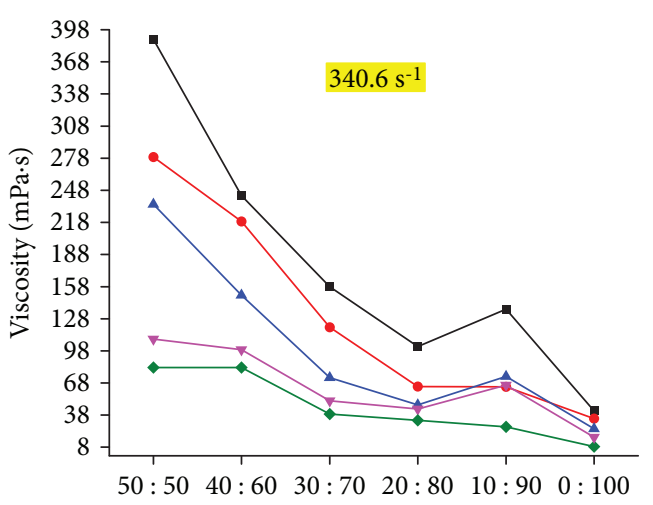

Oil-water ratio

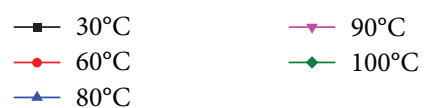

(d)

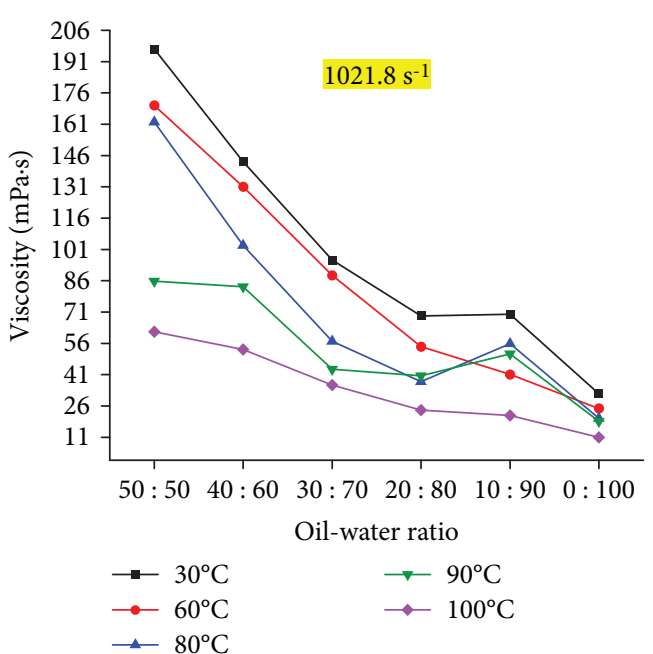

(f)

FIGURE 2: The relationship between the oil-water ratio and viscosity under different shear rates. 


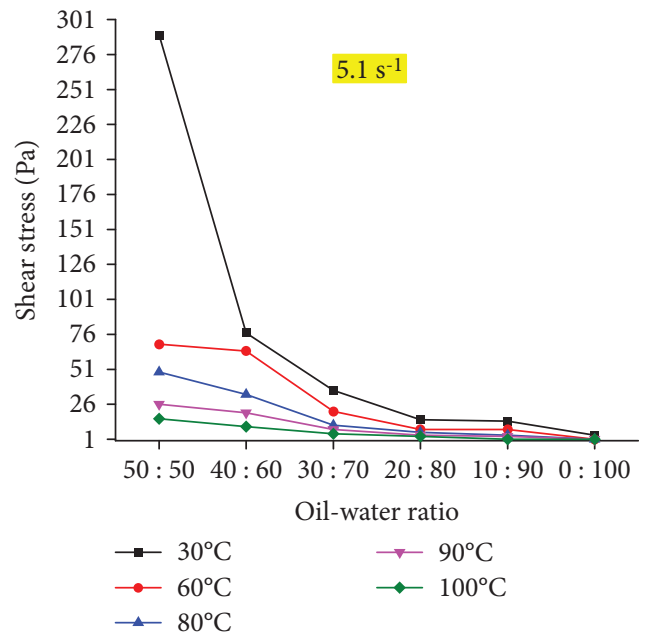

(a)

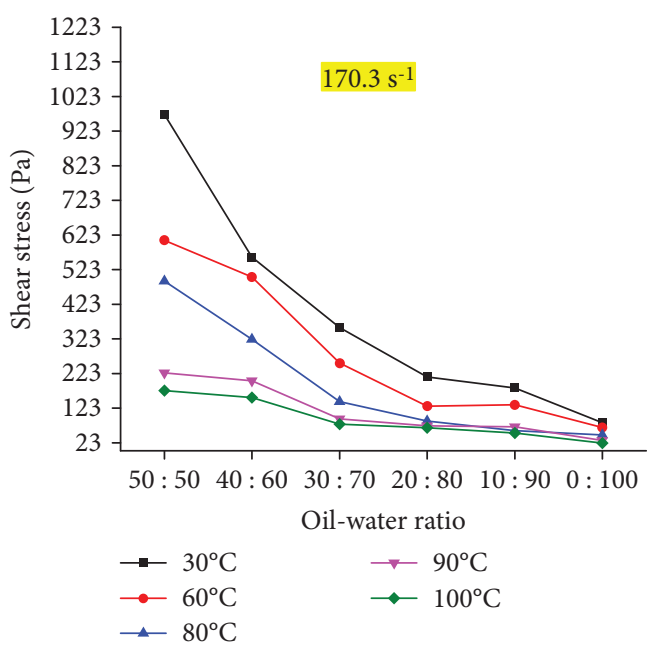

(c)

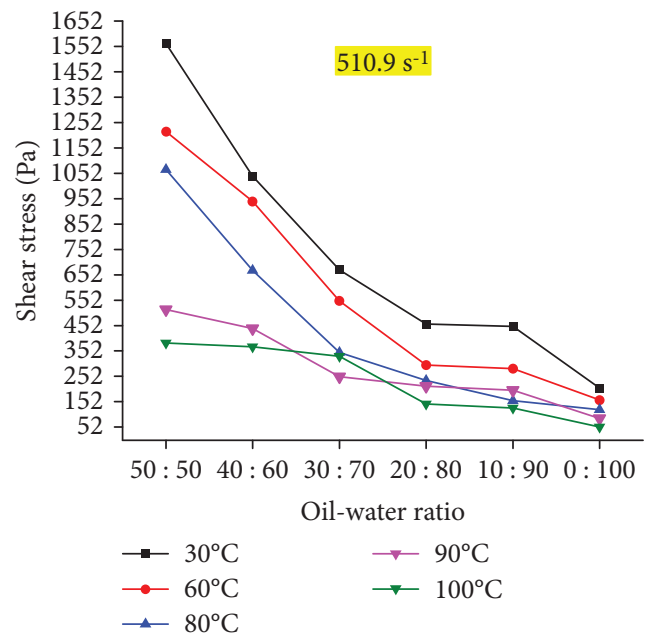

(e)
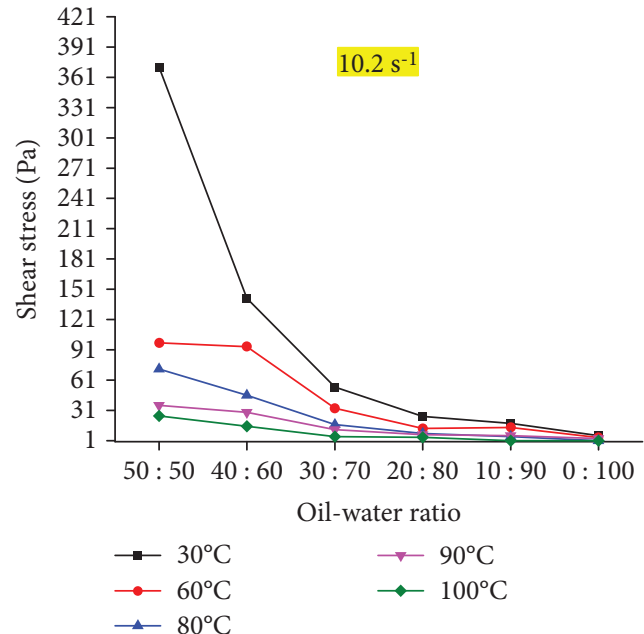

(b)

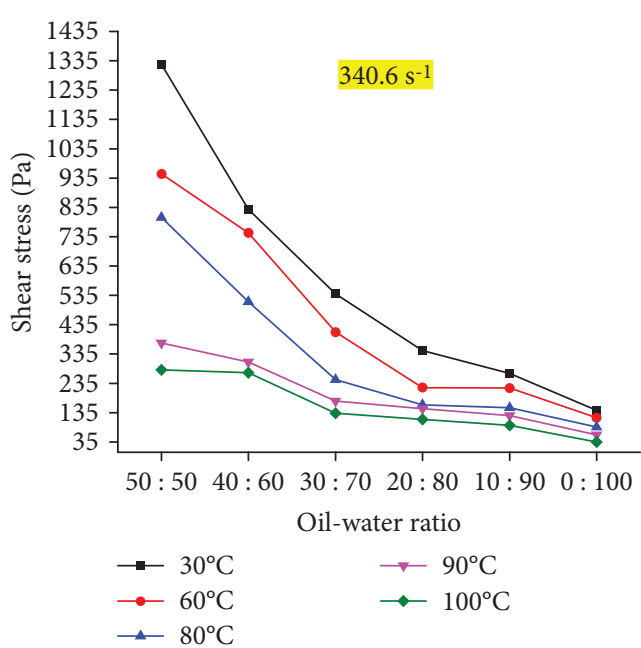

(d)

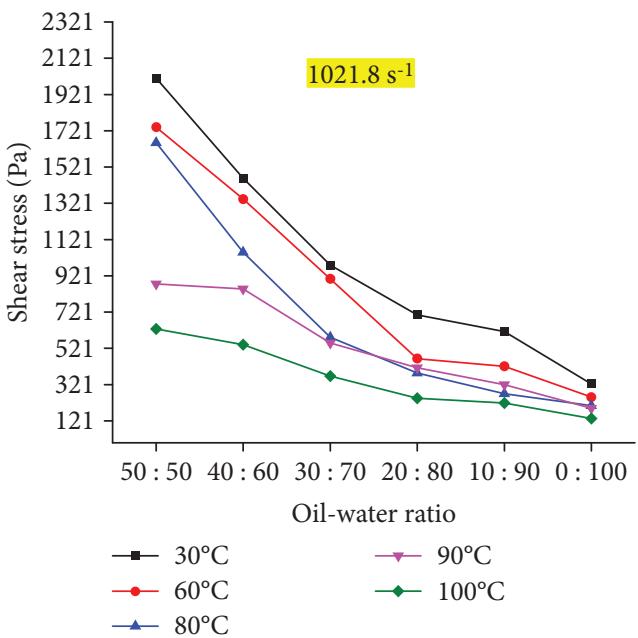

(f)

FIgURE 3: The relationship between the oil-water ratio and shear stress at different shear rates.

solution. The apparent viscosity of the HEC brine solution reduced from $71 \mathrm{mPa} \cdot \mathrm{s}$ to $16 \mathrm{mPa} \cdot \mathrm{s}$, reduced by $77.46 \%$, at a higher shear rate. However, the HEC emulsion remained about the same. However, under the same conditions, the tendency of shear stress did not keep a good consistency. With the increase in shear rate, the shear stress revealed 


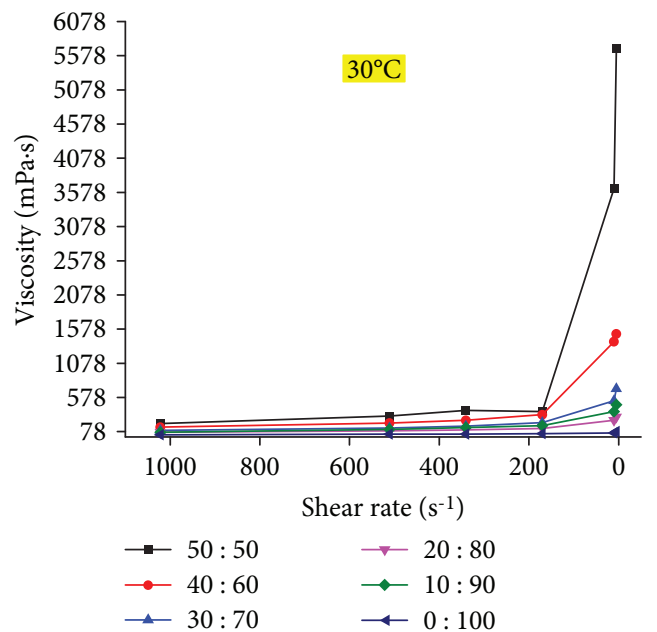

(a)

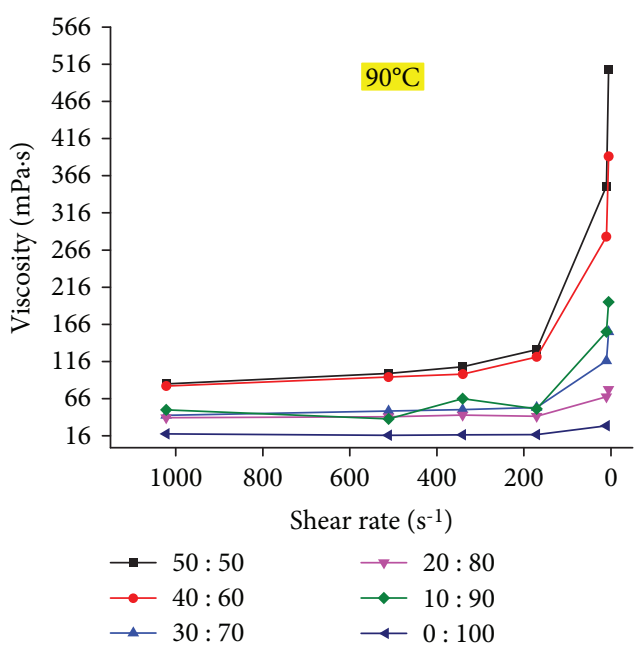

(b)

FIGURE 4: The relationship between apparent viscosity and shear rate at different temperatures.

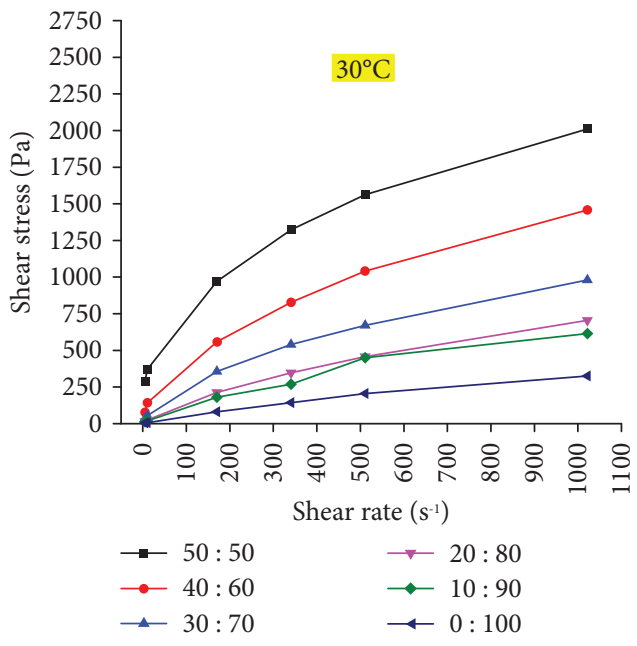

(a)

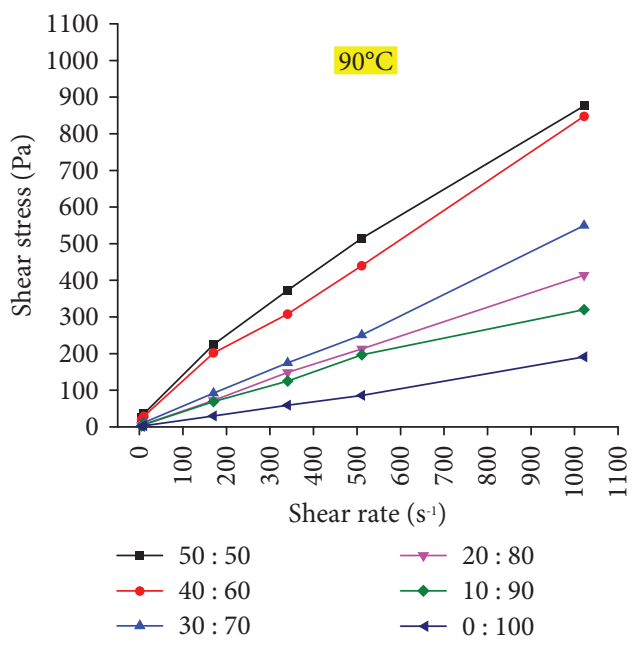

(b)

Figure 5: The relationship between shear strength and shear rate at different temperatures.

an uptrend at $30^{\circ} \mathrm{C}$. When the shear rate was lower than $170.3 \mathrm{~S}^{-1}$, the shear stress increased sharply; when the shear rate was greater than $170.3 \mathrm{~S}^{-1}$, the increase tended to be flat. At the temperature of $90^{\circ} \mathrm{C}$, the linear relationship between shear stress and shear rate was shown, but overall shear stress was much smaller than that at $30^{\circ} \mathrm{C}$. On the whole, the HEC emulsion solution expressed better rheological properties, which is good for drilling suspended sand and reducing drilling drag.

3.3. Constant Oil-Water Ratio. Under the constant oil-water ratio $50: 50,40: 60,30: 70,20: 80,10: 90,0: 100$ (oil-free) conditions, the rheological parameters of HEC emulsion were measured at different temperatures; the experimental results are shown in Figures 6 and 7.
The relationships between apparent viscosity and shear rate with different oil-water ratios are shown in Figure 6. The results shown in Figure 6 displayed that the apparent viscosity decreased with the increase in shear rate. As was shown in Figure 6, the apparent viscosity of HEC diesel oil emulsion was affected by the shear rate. At the temperature of $30^{\circ} \mathrm{C}$ and shear rate of $5.1 \mathrm{~S}^{-1}$, the viscosity increased from $78.4 \mathrm{mPa} \cdot \mathrm{s}$ to $5686 \mathrm{mPa} \cdot \mathrm{s}$, nearly 71.5 times, with the oilwater from $0: 100$ to $50: 50$. In contrast, with the equivalent change in the ratio, the viscosity increased from $12.3 \mathrm{mPa} \cdot \mathrm{s}$ to $61.5 \mathrm{mPa} \cdot \mathrm{s}$, increased by 4 times at the temperature of $100^{\circ} \mathrm{C}$ and shear rate of $5.1 \mathrm{~S}^{-1}$. This trend of viscosity decrease is due to thermal motion of the molecule. Under the high temperature, the acceleration of the relative motion of intermolecular in liquids wrecks formation of floc and cuts 


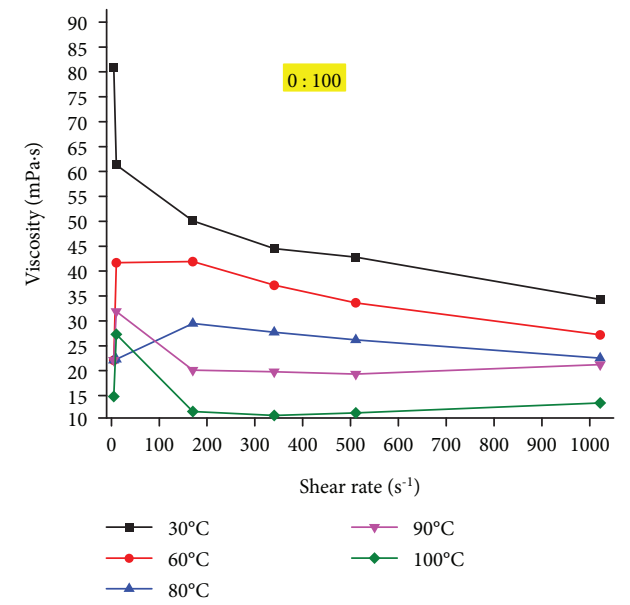

(a)

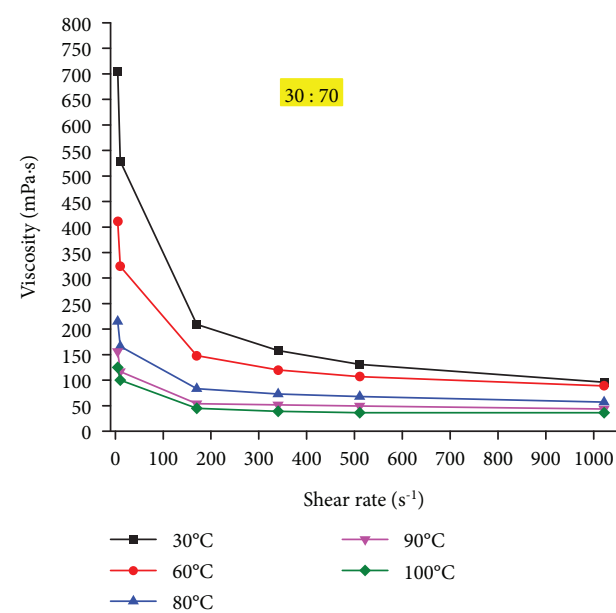

(c)

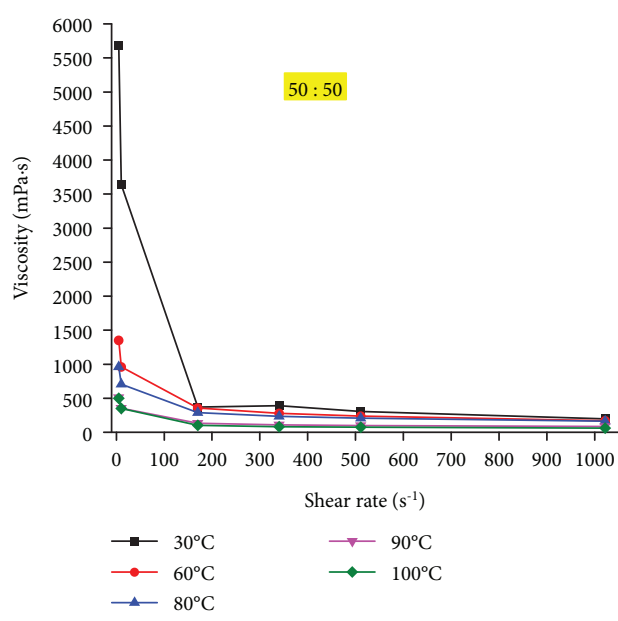

(e)

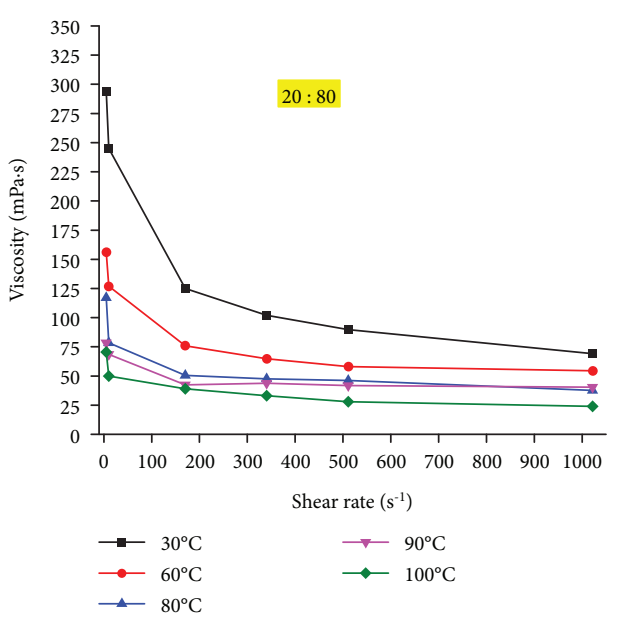

(b)

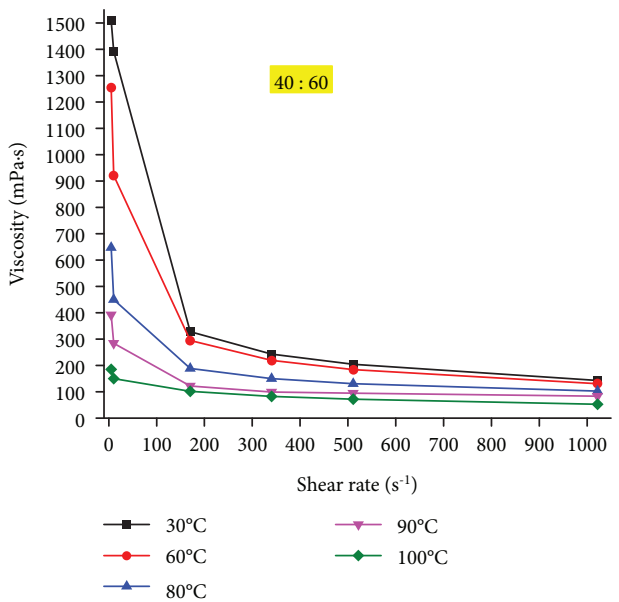

(d)

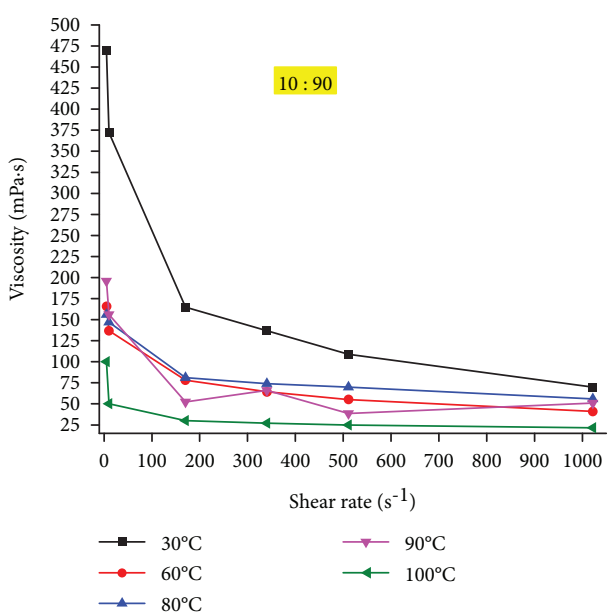

(f)

FIGURE 6: The relationship between apparent viscosity and shear rate of HEC emulsion solution having different oil-water ratios.

down the flocculating effect resulting in viscosity reduction. At the temperature of $100^{\circ} \mathrm{C}$, lower oil-water HEC emulsion almost lost its viscoelasticity and could not meet the requirements of the suspension. Conversely, higher oil- water HEC emulsion still could hold a certain viscosity which was greater than $\mathrm{mPa} \cdot \mathrm{s}$ and could transport cuttings in the process of drilling and completion of horizontal well in order to effectively prevent the formation of the 


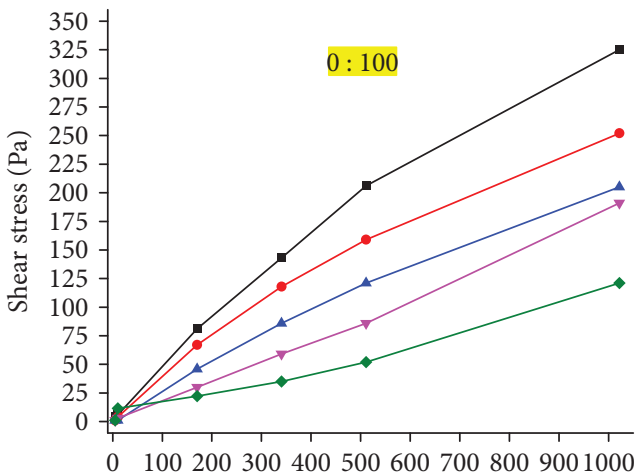

Shear rate $\left(\mathrm{s}^{-1}\right)$

$$
\begin{aligned}
& \rightarrow 30^{\circ} \mathrm{C} \\
& \rightarrow 60^{\circ} \mathrm{C} \\
& \rightarrow-80^{\circ} \mathrm{C}
\end{aligned}
$$

(a)

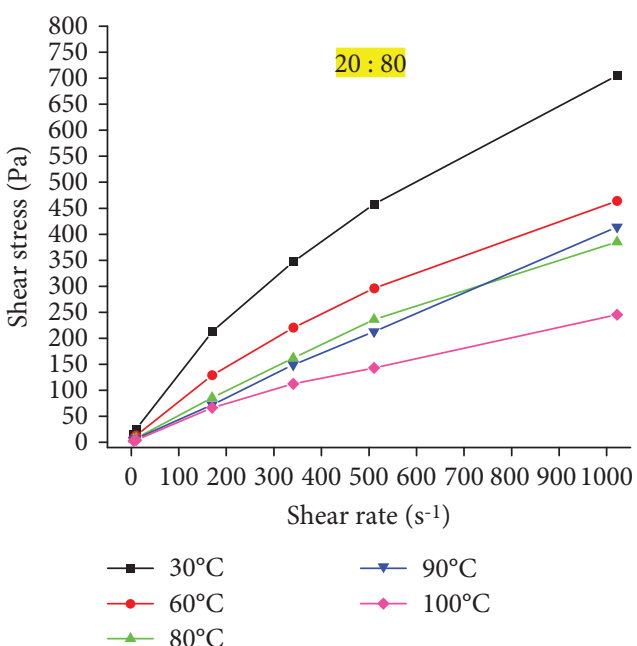

(c)

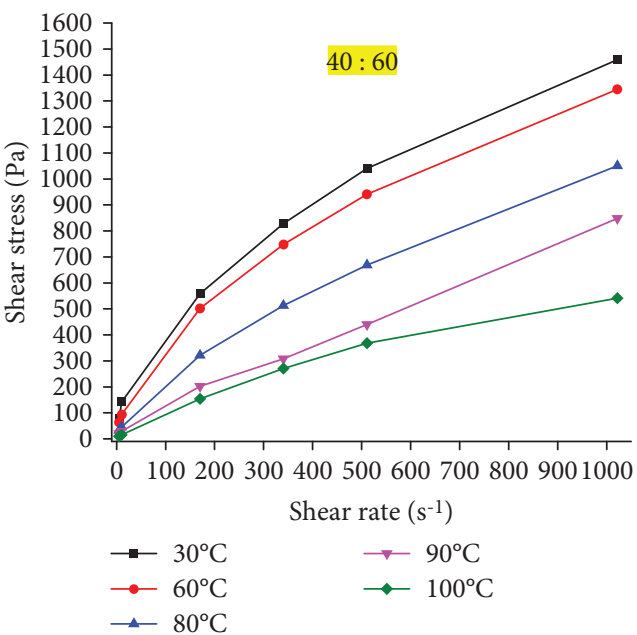

(e)

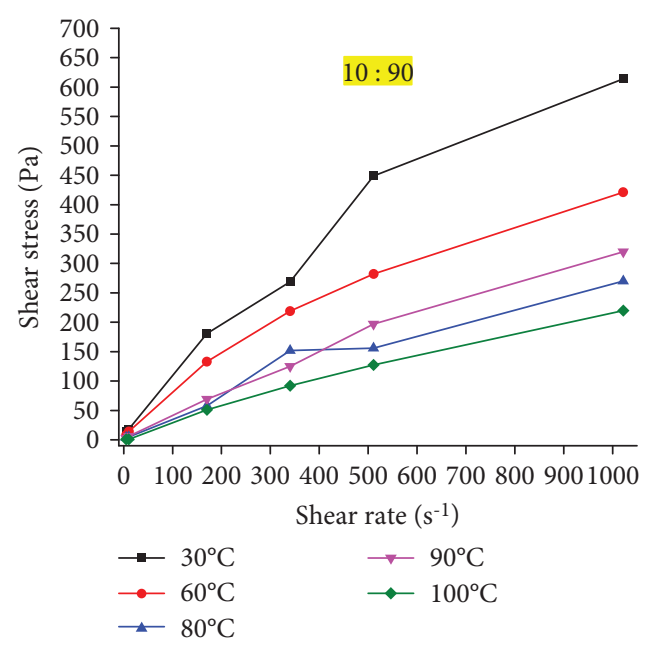

(b)

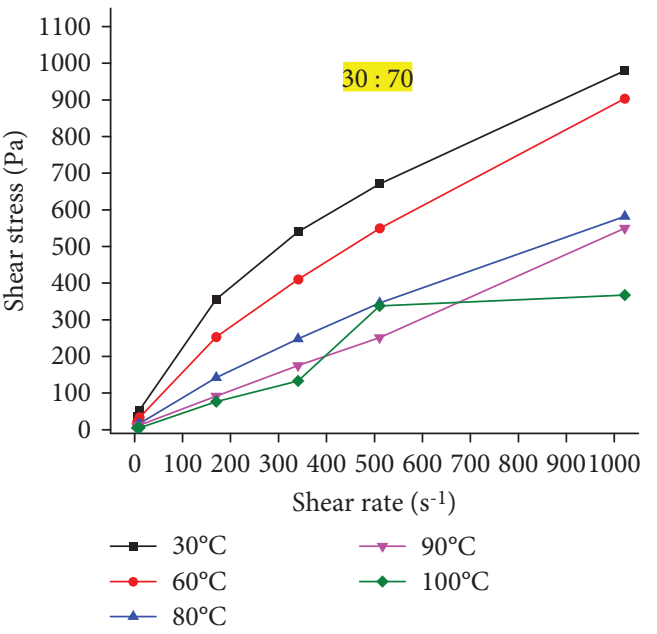

(d)

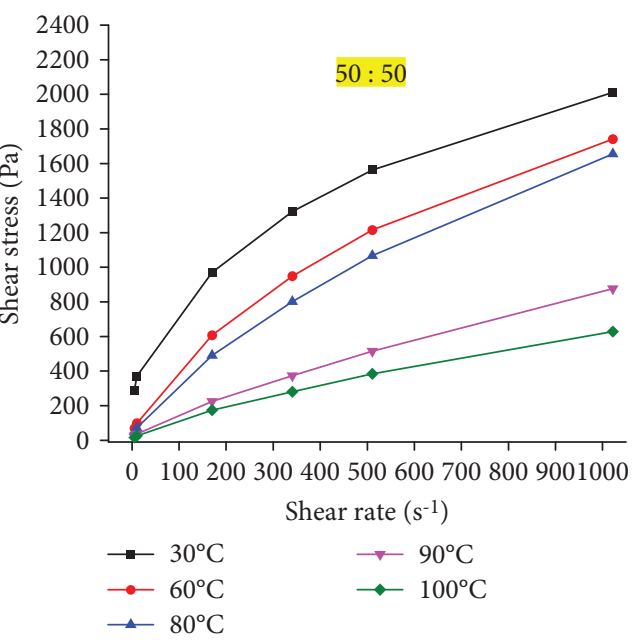

(f)

FIGURE 7: Relationships between the shear stress of different oil-water ratios of HEC and shear rate.

cutting bed, which expressed that higher oil-water emulsion could improve the thermal ability under the same dosage of HEC.
The relationships between shear stress and shear rate of HEC emulsion solution are shown in Figure 7, whose oilwater ratios were $0: 100$ (oil-free), 10:90, 20:80, 30:70, 


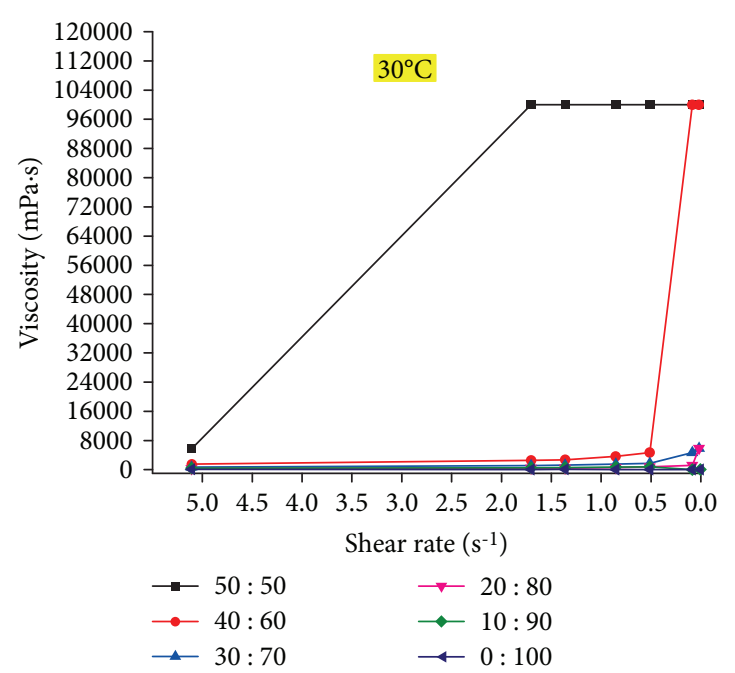

(a)

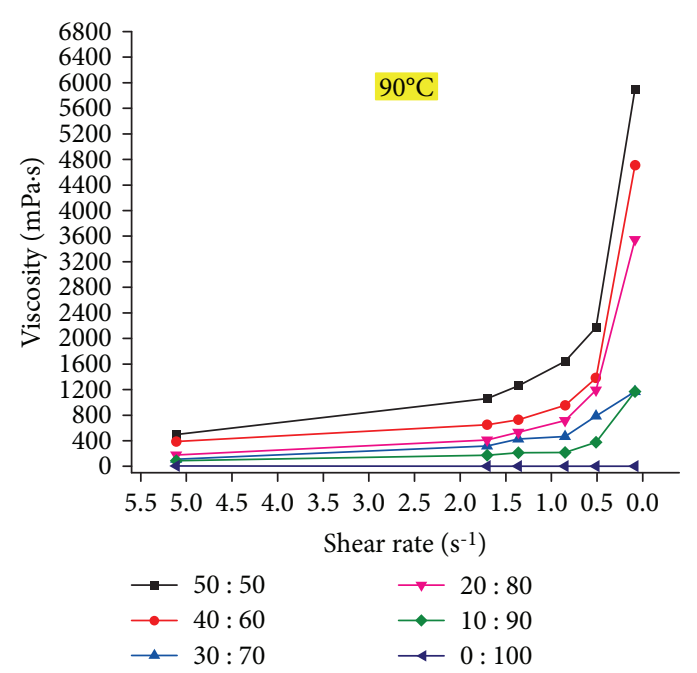

(b)

FIGURE 8: The relationship between shear rate and viscosity at different temperatures.

$40: 60$, and $50: 50$, respectively. As shown in Figure 7, it could be found that with the increase in shear rate, the shear stress tended to increase. With the increase in the oil-water ratio, the change in shear stress also increased and both changes showed good consistency. When the oil-water ratio was less than $20: 80$, the shear strength increased linearly with the increase in shear rate, which is due to the fact that the low number of free and independent droplets could cause less friction between droplets and internal friction decrease, showing the characteristics of near Newton fluid. However, when the oil-water ratio was greater than $20: 80$, the increase in shear stress is divided into two phases. In the first phase, the shear stress increased obviously with the increase in shear rate when the shear rate was less than $170.3 \mathrm{~S}^{-1}$. In the second phase, the change was smoother when the shear rate was greater than $170.3 \mathrm{~S}^{-1}$, which indicated that oil can play the role of lubrication.

As was shown in Figure 7, it was suggested that when the oil-water ratio was greater than $20: 80$, viscosity coefficient $n$ was less than 1. According to the power law model, the greater the oil-water ratio was, the smaller the $n$ was, and the greater the consistency index $K$ of emulsion was, and the experimental result has good consistency with it. Meanwhile, the decrease in $n$ was likely to improve the ratio of yield stress to plastic, which could turn gradually the turbulence of the annulus space into a flat plate laminar flow. This flow pattern can effectively avoid the erosion of drilling and completion fluid for the sidewall, which was conducive to the protection of borehole stability. Under the constant oilwater condition, the higher the temperature was, the smaller the $K$ was, the greater the $n$ was, and the stronger the nonNewtonian characteristic was, and the variation trend is close to the power function, which expressed that the system has a better rheological property and could be used in drilling fluid by combining with other additives.

3.4. Low Shear Rate. In the drilling process, high elastic area could be formed in the vicinity of the borehole wall if the drilling fluid system has a high viscosity at low shear rate. This characteristic of high viscosity at low shear rate is good for sand-carrying and could effectively prevent the formation of sand bed [21]. Through analyzing the rheological property under lower shear stress, we could determine whether the system is fit for drilling. The experimental results are shown in Figures 8 and 9.

The relationship between the apparent viscosity, shear stress, and shear rate is shown in Figures 8 and 9. The viscosity increased, and the shear stress decreased with the decrease in shear rate, which indicated that more stable mesh structures were formed at a low shear rate, resulting in the increase in viscosity. At the temperature of $30^{\circ} \mathrm{C}$, the shear rate of less than $1.7 \mathrm{~S}^{-1}$, the viscosity of the HEC emulsion with oil-water ratio of $50: 50$ was up to $99999 \mathrm{mPa} \cdot \mathrm{s}$, which has good capacity of sand-carrying and could effectively overcome the problem of sand carrying difficulty for horizontal or deviated well easing to form sand bed. While the viscosity of the HEC solution using brine $(0: 100)$ as solvent was extremely low, only through putting more HEC to increase the viscosity solves the problem of carrying cuttings, in which there was no doubt that the above method adds the drilling cost and anti-temperature effect of the HEC solution which was not better than HEC emulsion. As was shown in Figures 8 and 9 , with the increase in the oil-water ratio, viscosity and shear stress kept a good consistency in the decrease. The oil-water ratio could be further improved to achieve a better performance of temperature resistance, tackifying, and lubricity, which expressed that the HEC emulsion had a better suspension property and thermal stability than aqueous solution and could be used in drilling fluid by combining with other additives to improve the drilling efficiency and reduce the drilling cost.

3.5. Emulsion Stability. Sedimentation is one of the most conventional and intuitionistic experiments analyzing emulsion stability. In the paper, it was adopted to analyze the emulsion stability of HEC emulsion. The experimental steps were as 


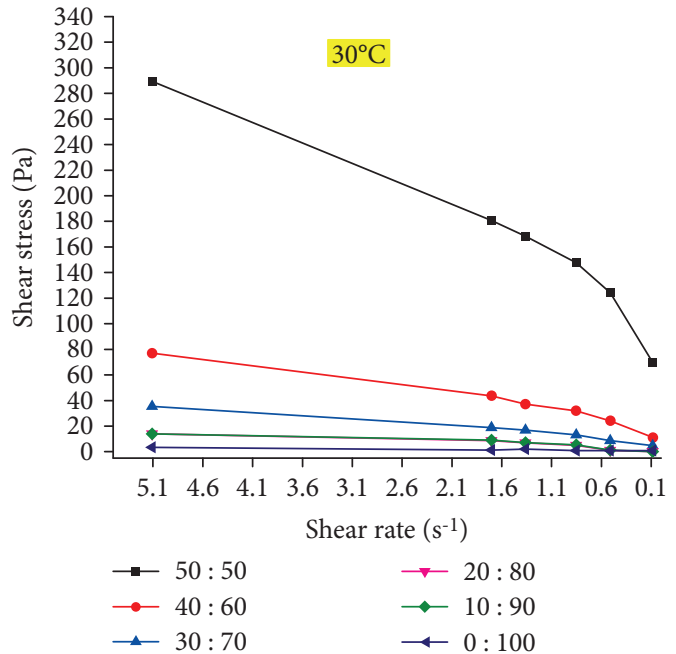

(a)

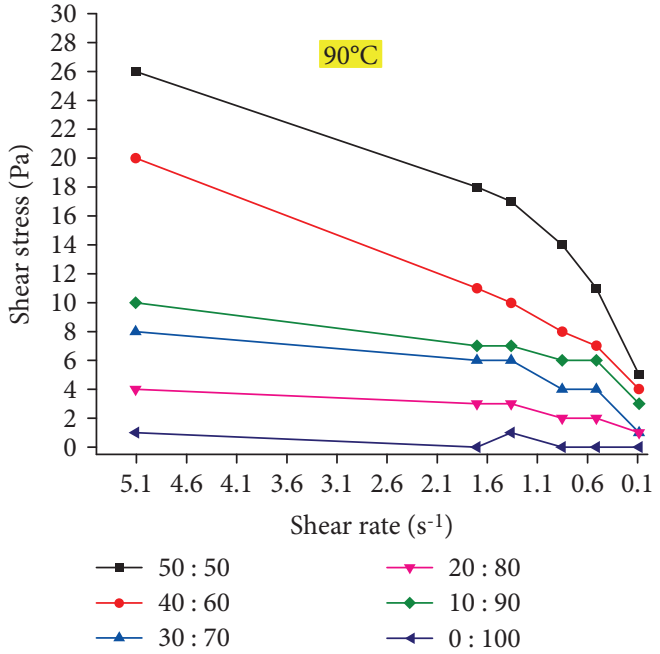

(b)

Figure 9: The relationship between shear rate and shear stress at different temperatures.

TABLE 2: The evaluation of sedimentation stability.

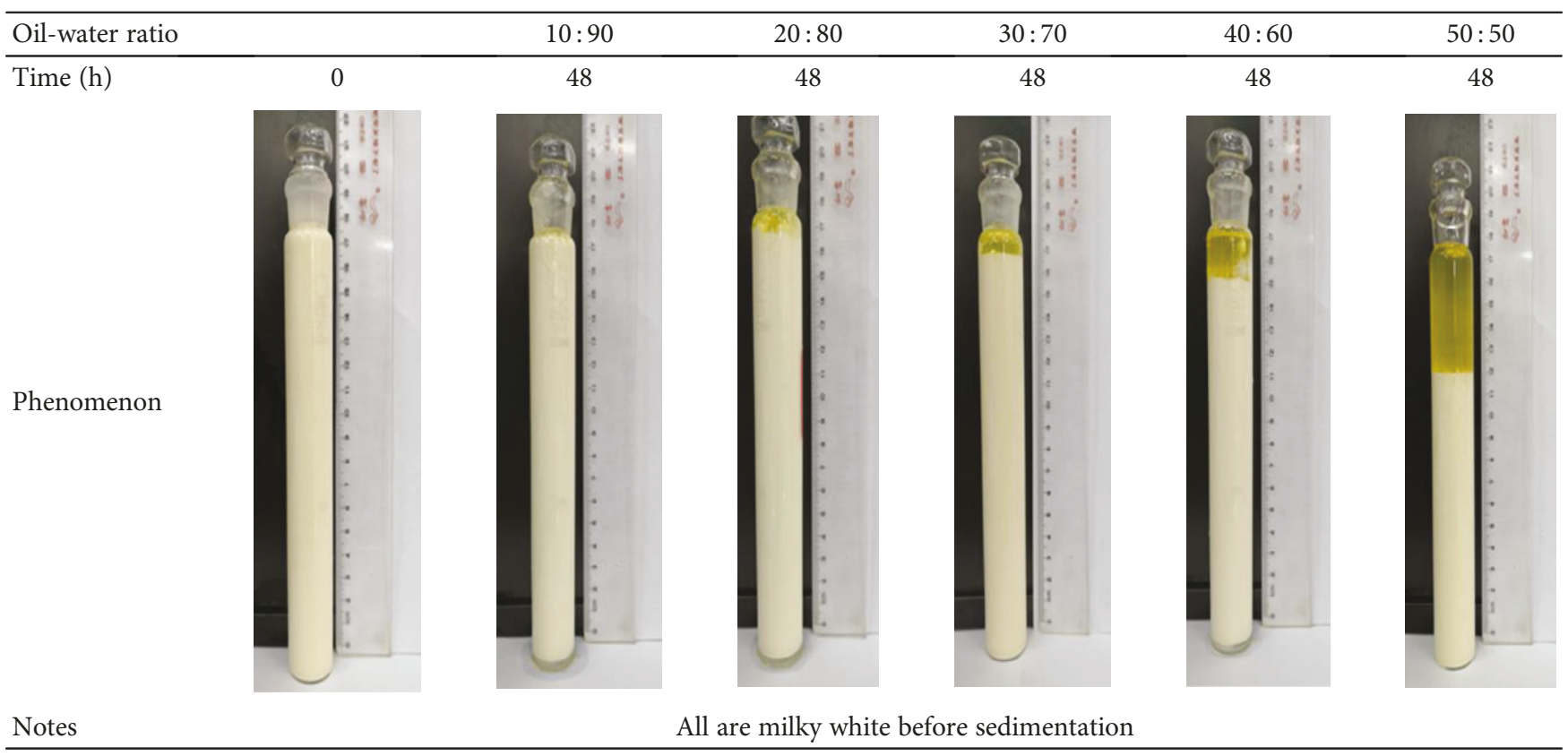

follows: let HEC emulsion stir and stand for 48 hours in a colorimetric tube, and then observe the change and difference between the upper and lower sections in the colorimetric tube. The results are shown in Table 2.

Table 2 shows that the bigger the oil-water ratio, the more upper separator liquid there is; there was a small amount of change between $20: 80$ and $30: 70$, and it was still in a reasonable range. However, the separator liquid was more than $2 \mathrm{~cm}$ when the oil-water ratio was more than 30:70 and it was even about 1/3 when the oil-water was 50:50, which meant that the emulsion stability was worse when the oil-water ratio was more than 30:70. Besides, we analyzed the stability by temperature resistance experiment and the results are shown in Figure 10. It can be seen that the surface morphology of HEC emulsion after hot rolling lasting $16 \mathrm{~h}$ at $100^{\circ} \mathrm{C}$ changed from ivory to yellow (all are milky white before hot rolling) with the increase in the oil-water ratio.

This phenomenon shown in Figure 10 could be illustrated that a higher temperature had an effect on the emulsifier and led HEC emulsion with a higher oil-water ratio to be unstable. Further, oil and water were separated, with oil floating on the surface, and the solution surface appeared with the same color as that of diesel. 


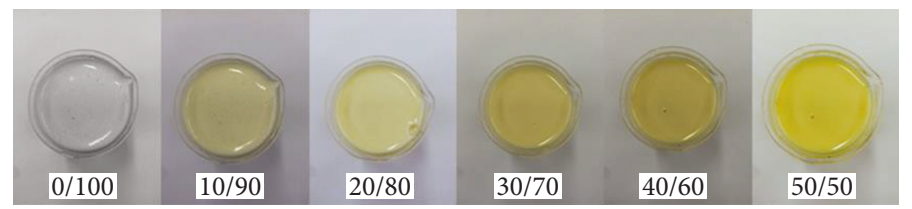

Figure 10: The state of HEC emulsion solution after hot rolling at $100^{\circ} \mathrm{C}$ after $16 \mathrm{~h}$.

By comparing the results shown above, there was good coherence and it was concluded that the emulsion solution of the too high oil-water ratio was not suitable for the tackifier of HEC because of its poor thermal stability and emulsion stability and the oil-water ratio $30: 70$ emulsion was the optimal solution, which expressed excellent thermal stability and emulsion stability.

\section{Conclusion}

Based on the experimental results, in Sections 3.1, 3.2, 3.3, and 3.4, the following conclusions can be made:

(1) Diesel oil emulsion can be used in the polymer drilling fluid system. Under the same dosage of the HEC, diesel oil emulsion, as a solvent, can significantly improve the rheological stability of polymer HEC at room temperature and higher temperature and can enhance the lubrication and viscoelasticity of polymer drilling fluid, which is good for improving the drilling speed and reducing the reservoir damage and drilling cost

(2) When the ratio was more than 20:80, the HEC emulsion has a better rheological property and thermal stability, but when the ratio was more than $40: 60$, it expressed oil-water separation as shown in Figure 10 and Table 2, the oil floating on the surface, and the solution appeared with the same color as that of diesel. So, the emulsion solution with an oilwater ratio of 30:70 was an ideal increasing solvent for HEC

(3) The dosage and variety of other additives need to ascertain for the HEC emulsion drilling fluid, such as emulsifier and filtrate reducer if we want to get a system on it. Besides, the microcosmic displacement mechanism between HEC and oil-water is a complex and meaningful topic and needs to be studied independently to learn more about the emulsion stability of HEC emulsion

\section{Data Availability}

The data used to support the findings of this study are available from the corresponding author upon request. The email is sxm310426@126.com.

\section{Conflicts of Interest}

The authors declare that they have no conflicts of interest.

\section{References}

[1] J. Abdo and M. D. Haneef, "Nano-enhanced drilling fluids: pioneering approach to overcome uncompromising drilling problems," Journal of Energy Resources Technology, vol. 134, no. 1, article 014501, 2012.

[2] N. V. Boyou, I. Ismail, W. R. Wan Sulaiman et al., "Experimental investigation of hole cleaning in directional drilling by using nano-enhanced water-based drilling fluids," Journal of Petroleum Science and Engineering, vol. 176, pp. 220-231, 2019.

[3] J. H. Cai, H. Liu, Y. Chen, and C. B. Xiao, "Study on degradable drilling fluid system for coalbed methane horizontal drilling," Journal of China Coal Society, vol. 36, no. 10, pp. 1683-1688, 2011.

[4] M. M. Dardir, S. Ibrahime, M. Soliman, S. D. Desouky, and A. A. Hafiz, "Preparation and evaluation of some esteramides as synthetic based drilling fluids," Egyptian Journal of Petroleum, vol. 23, no. 1, pp. 35-43, 2014.

[5] A. M. Salem Ragab and A. Noah, "Reduction of formation damage and fluid loss using nano-sized silica drilling fluids," Petroleum Technology Development Journal, vol. 2, pp. 7588, 2014.

[6] C.-H. Choi, U. Ulmanella, J. Kim, C.-H. Ho, and C.-H. Kim, "Effective slip and friction reduction in nanograted superhydrophobic microchannels," Physics of Fluids, vol. 18, no. 8, article 087105, 2006.

[7] M. Sadeghalvaad and S. Sabbaghi, "The effect of the TiO 2 /polyacrylamide nanocomposite on water-based drilling fluid properties," Powder Technology, vol. 272, pp. 113-119, 2015.

[8] M. Azam, A. Yassin, and A. Kamis, "Palm oil derivative as a based fluid in formulating oil based drilling mud," in SPE Latin America Petroleum Engineering Conference, Rio de Janeiro, Brazil, October 1990.

[9] D. L. Carbajal, C. N. Burress, W. Shumway, and Y. Zhang, "Combining proven anti-sag technologies for HPHT north sea applications: clay-free oil-based fluid and synthetic, submicron weight material," in SPE/IADC Drilling Conference and Exhibition, Amsterdam, The Netherlands, March 2009.

[10] F. T. G. Dias, R. R. Souza, and E. F. Lucas, "Influence of modified starches composition on their performance as fluid loss additives in invert-emulsion drilling fluids," Fuel, vol. 140, pp. 711-716, 2015.

[11] J. Hermoso, F. Martinez-Boza, and C. Gallegos, "Influence of viscosity modifier nature and concentration on the viscous flow behaviour of oil-based drilling fluids at high pressure," Applied Clay Science, vol. 87, no. 1, pp. 14-21, 2014.

[12] J. Hermoso, F. Martinez-Boza, and C. Gallegos, "Influence of aqueous phase volume fraction, organoclay concentration and pressure on invert-emulsion oil muds rheology," Journal of Industrial and Engineering Chemistry, vol. 22, pp. 341349, 2015. 
[13] F. Civan, Reservoir Formation Damage, Gulf Professional Publishing, 2007.

[14] L. F. Lopes, B. O. Silveira, and R. B. Moreno, "Loss circulation and formation damage control on overbalanced drilling with different formulations of water based drill-in fluids on sandstone reservoir," in ASME 2012 31st International Conference on Ocean, Offshore and Arctic Engineering, pp. 859-869, Rio de Janeiro, Brazil, July 2012.

[15] X. Zhao, Z. Qiu, B. Sun, S. Liu, X. Xing, and M. Wang, "Formation damage mechanisms associated with drilling and completion fluids for deepwater reservoirs," Journal of Petroleum Science and Engineering, vol. 173, pp. 112-121, 2019.

[16] S. Ding, H. Liu, L. Bai, W. Yang, and W. Hao, "Thixotropy and anti-thixotropy of hydroxyethyl cellulose aqueous solutions," Materials Review, vol. 2013, no. 20, p. 23, 2013.

[17] B. Nystroem and B. Lindman, "Dynamic and viscoelastic properties during the thermal gelation process of a nonionic cellulose ether dissolved in water in the presence of ionic surfactants," Macromolecules, vol. 28, no. 4, pp. 967-974, 1995.

[18] D. Mech and J. S. Sangwai, "Effect of molecular weight of polyethylene glycol (PEG), a hydrate inhibitive water-based drilling fluid additive, on the formation and dissociation kinetics of methane hydrate," Journal of Natural Gas Science and Engineering, vol. 35, pp. 1441-1452, 2016.

[19] N. A. al Sandouk-Lincke, J. Schwarzbauer, V. Antic et al., "Off-line-pyrolysis-gas chromatography-mass spectrometry analyses of drilling fluids and drill cuttings - identification of potential environmental marker substances," Organic Geochemistry, vol. 88, pp. 17-28, 2015.

[20] X. Villegas-Pañeda, S. Pérez-Casas, E. Hernández-Baltazar, and A. E. Chávez-Castellanos, "Study of interactions between octyl- $\beta$-D-glucopyranoside and the hydroxyethyl-cellulose biopolymer in aqueous solution," Journal of Chemical Thermodynamics, vol. 79, pp. 69-75, 2014.

[21] W. Jian, Z. Rong, and N. Mingshun, "Research and application of HRD weak gel drilling fluid," Natural Gas Exploration \& Development, no. 4, pp. 52-55, 2008. 

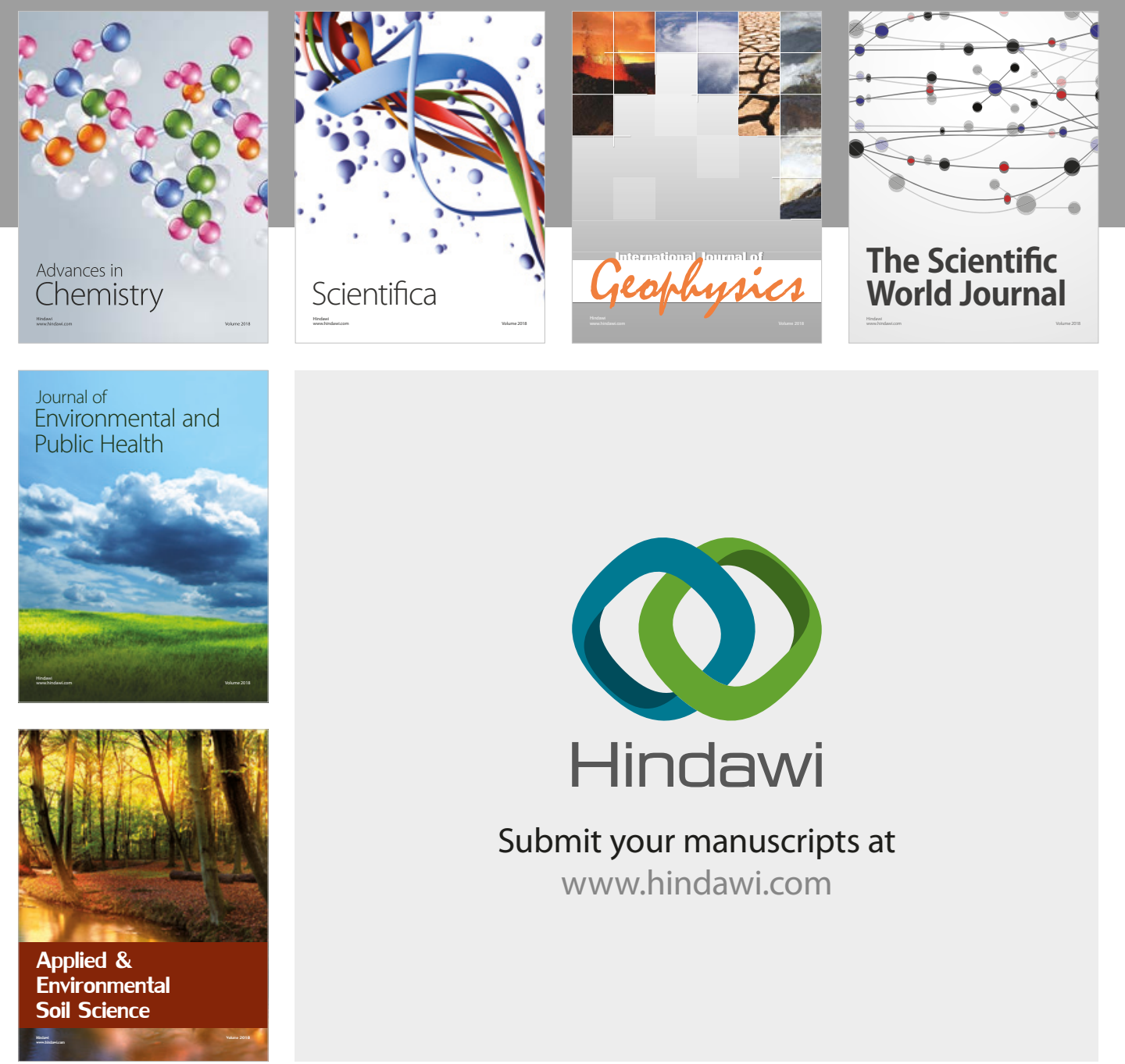

The Scientific

\section{World Journal}
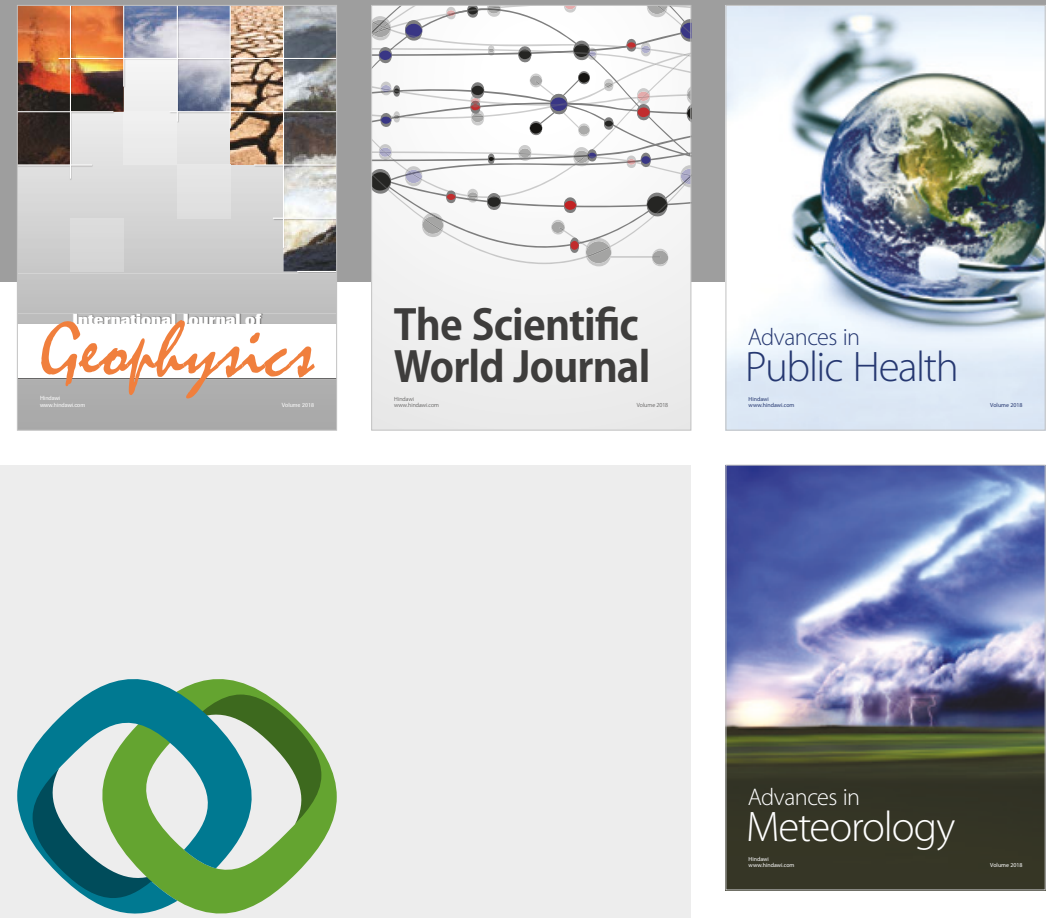

Advan

Public Health

\section{Hindawi}

Submit your manuscripts at

www.hindawi.com
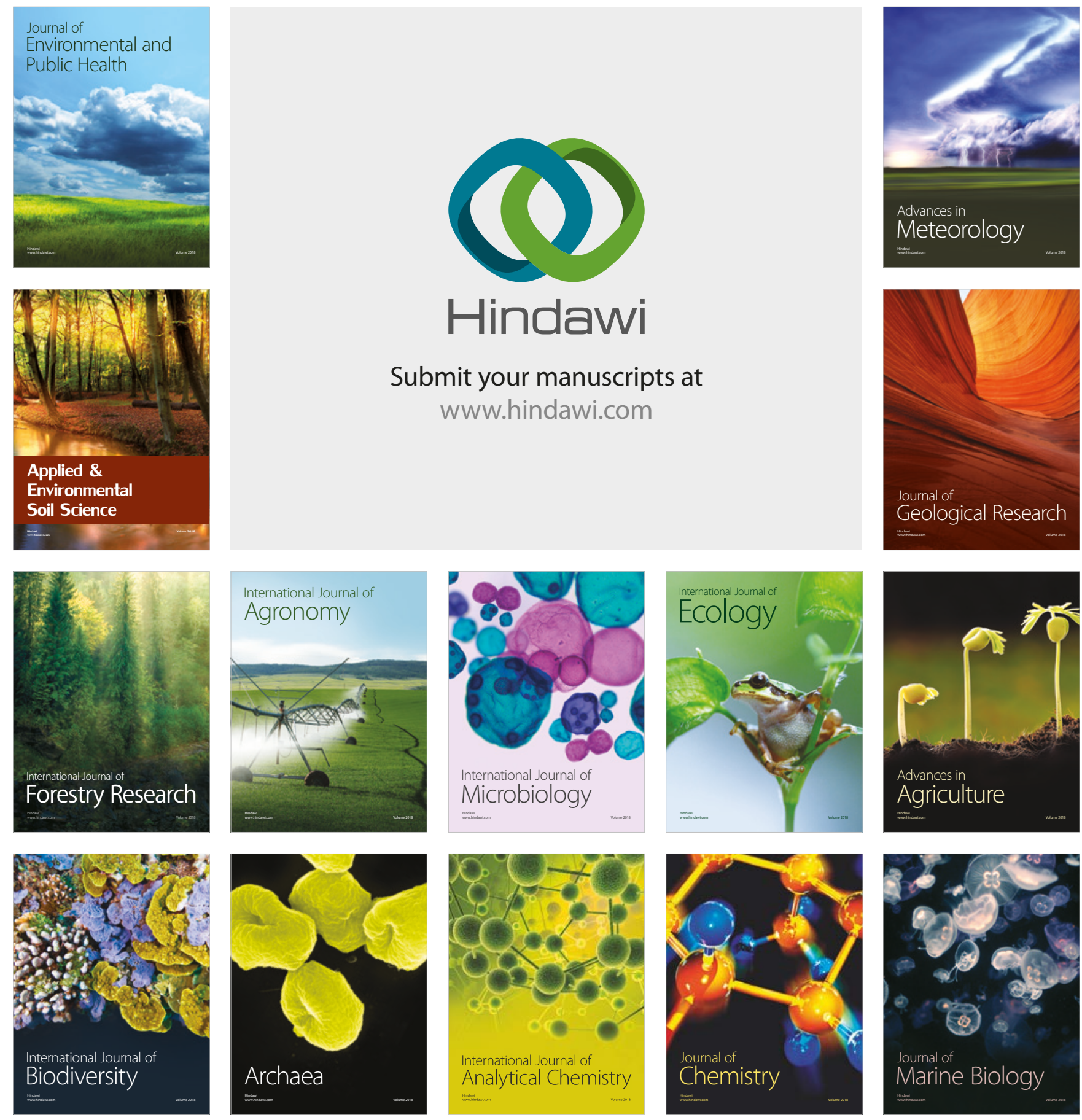